\title{
Recurrent embolotherapy in Dieulafoy's disease of the bronchus
}

\author{
Praveen Bhatia MRCPI ${ }^{1}$, MS Hendy FRCP ${ }^{1}$, E Li-Kam-Wa FRCP ${ }^{1}$, PK Bowyer FRCR ${ }^{2}$
}

\begin{abstract}
P Bhatia, MS Hendy, E Li-Kam-Wa, PK Bowyer. Recurrent embolotherapy in Dieulafoy's disease of the bronchus. Can Respir J 2003;10(6):331-333.
\end{abstract}

Dieulafoy's disease is a vascular anomaly characterized by the presence of a dysplastic artery that is related to an epithelial ulcer. The French surgeon Georges Dieulafoy first described it in 1898. Most frequently, it is a gastrointestinal condition, but occurrence in the bronchus has been reported in a few cases. The case of a 52-year-old man with massive hemoptysis, for which he underwent successful embolotherapy 10 years previously, is described. Over the next 10 years, he had several hospital admissions due to hemoptysis, and he underwent successful embolotherapy on each occasion. This case report underlines the importance of bronchial arteriography as the investigation of choice for massive hemoptysis.

Key Words: Aberrant vessel; Bronchial artery angiogram; Dieulafoy's disease; Embolization; Massive hemoptysis; Tuberculosis

\section{Embolothérapie récurrente pour traiter la maladie Dieulafoy des bronches}

La maladie Dieulafoy est une anomalie vasculaire caractérisée par la présence d'une artère dysplasique liée à un ulcère épithélial. Le chirurgien français Georges Dieulafoy l'a décrite pour la première fois en 1898. La plupart du temps, il s'agit d'une condition gastro-intestinale, mais on a signalé des manifestations dans les bronches dans certains cas. On décrit le cas d'un homme de 52 ans souffrant d'une hémoptysie massive contre laquelle il a subi avec succès une embolothérapie dix ans auparavant. Au cours des dix années suivantes, il a fait plusieurs séjours à l'hôpital en raison d'une hémoptysie et a subi avec succès une embolothérapie à chaque occasion. Cette étude souligne l'importance de l'artériographie bronchique comme intervention de choix pour contrer une hémoptysie massive.

\begin{abstract}
$\mathrm{A}^{4}$ 42-year-old man was admitted to the hospital with a history of recurrent hemoptysis in September 1991. On the day of admission, he had coughed up approximately $300 \mathrm{~mL}$ of fresh blood. He was a smoker and had been treated for pulmonary tuberculosis 10 years previously. There were no other associated symptoms. At the time of admission, apart from a pulse rate of 100 beats/min, the clinical examination was normal. The patient's hemoglobin level was $135 \mathrm{~g} / \mathrm{L}$. A chest radiograph demonstrated bilateral upper lobe opacities suggestive of healed tuberculosis (Figure 1). Active pulmonary tuberculosis was excluded by negative sputum tests.

While in hospital, the hemoptysis continued, and two days after admission, the patient had a respiratory arrest after a bout of hemoptysis. He recovered spontaneously. The following day, his hemoglobin level dropped to $106 \mathrm{~g} / \mathrm{L}$. He underwent a fibreoptic bronchoscopy, which was normal. Bronchial washings did not grow any pathogenic organisms and no malignant cells were seen. A computed tomography scan of the chest showed apical pleural thickening and numerous cavities within the upper lobe apical segments. There was no evidence of any mycetoma or bronchiectasis. Bronchial angiography showed that the right bronchial artery was dilated and irregular, and extensive abnormal vessels were identified (Figure 2). Right bronchial artery embolization using microparticles (Figure 3) was performed successfully.
\end{abstract}

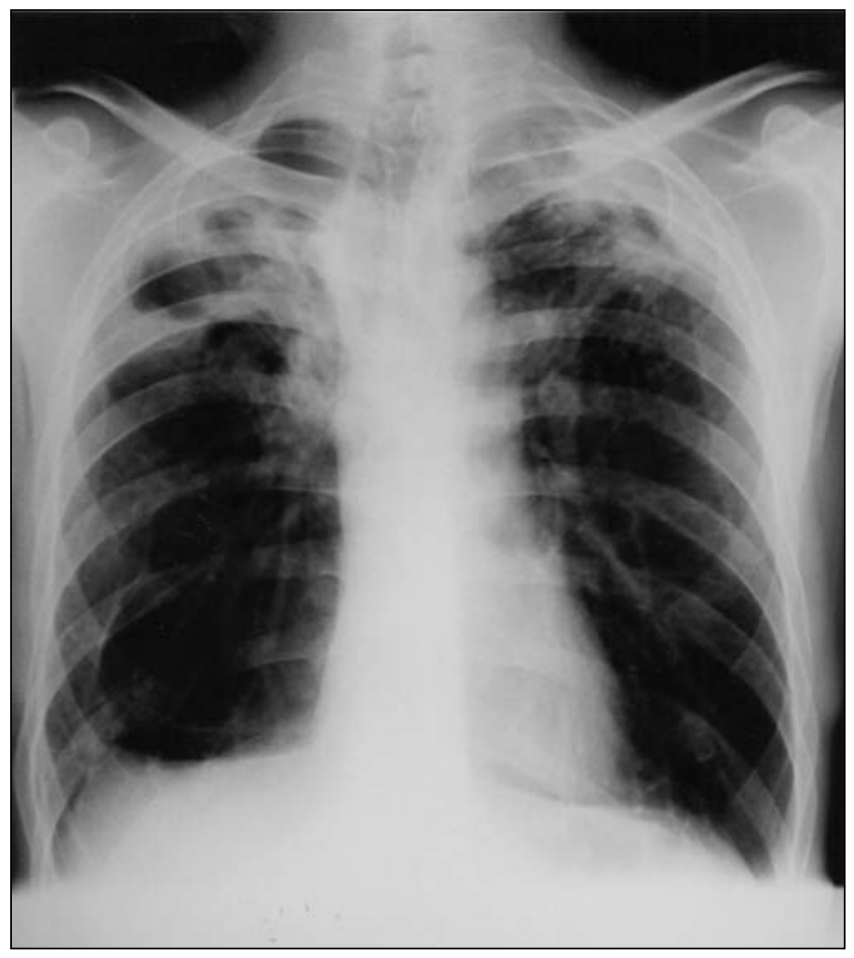

Figure 1) Chest $x$-ray showing bilateral healed upper lobe tuberculosis with cavity formation

${ }^{1}$ Department of Respiratory Medicine, ${ }^{2}$ Department of Radiology, Blackpool Victoria Hospital, Whinney Heys Road, Blackpool, United Kingdom Correspondence and reprints: Dr Praveen Bhatia, 7 Whinney Heys Road, Blackpool, FY3 8NP, United Kingdom. Telephone +44-1253-300000 ext 864, fax +44-1253-301783, e-mail naviapo@aol.com 


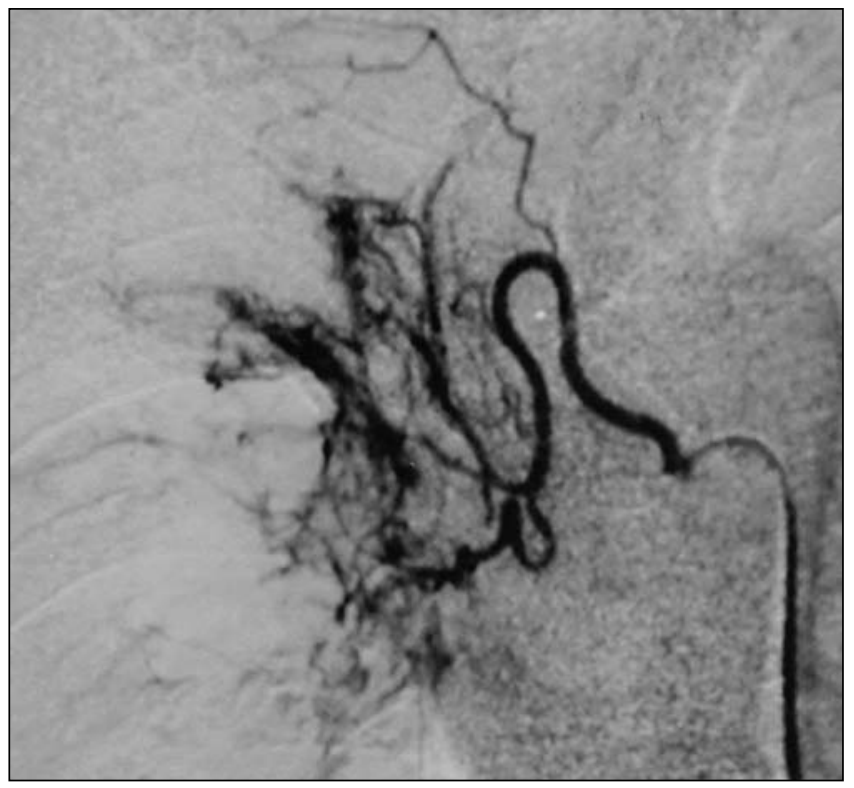

Figure 2) Bronchial angiogram on right side showing extensive abnormal vessels

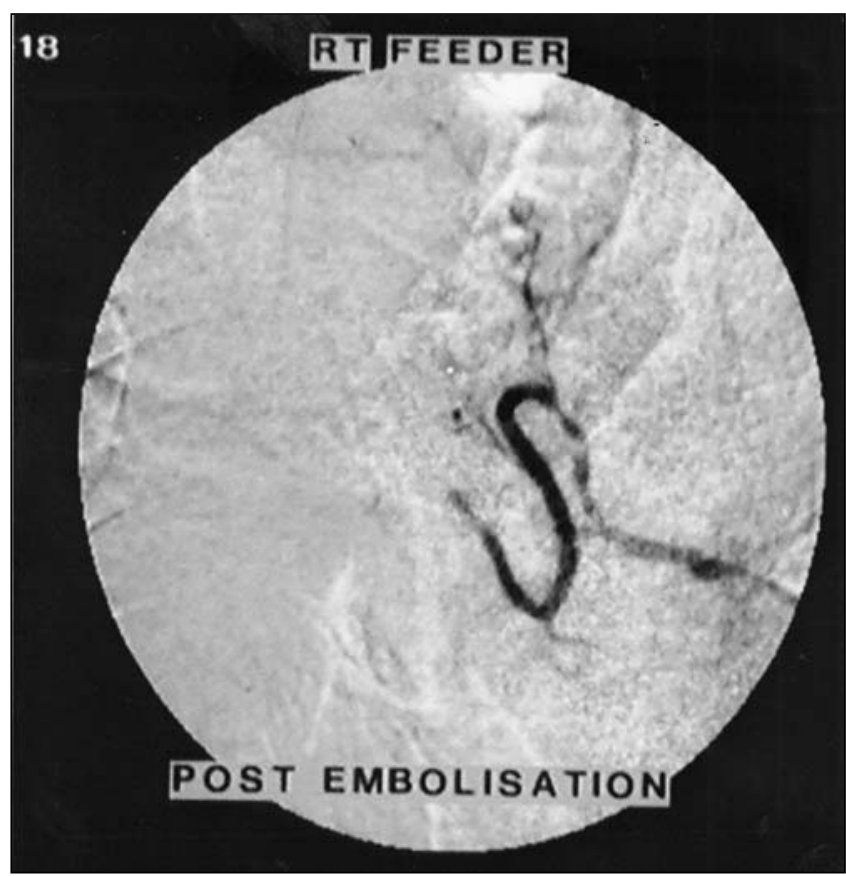

Figure 3) Bronchial angiogram demonstrating successful embolization

One year and one-half later, he was readmitted to the hospital with repeated episodes of hemoptysis. Bronchial arteriography again showed extensive abnormal vessels arising from the right bronchial artery (Figure 4). On the left side, arising from the internal mammary, a single vessel was found leading to extensive pleural-based abnormalities, which amounted to an arteriovenous malformation. Both the vessels were successfully embolized using tungsten coil.

He had further episodes of hemoptysis two years later and underwent bronchoscopy, which showed fresh blood in the left

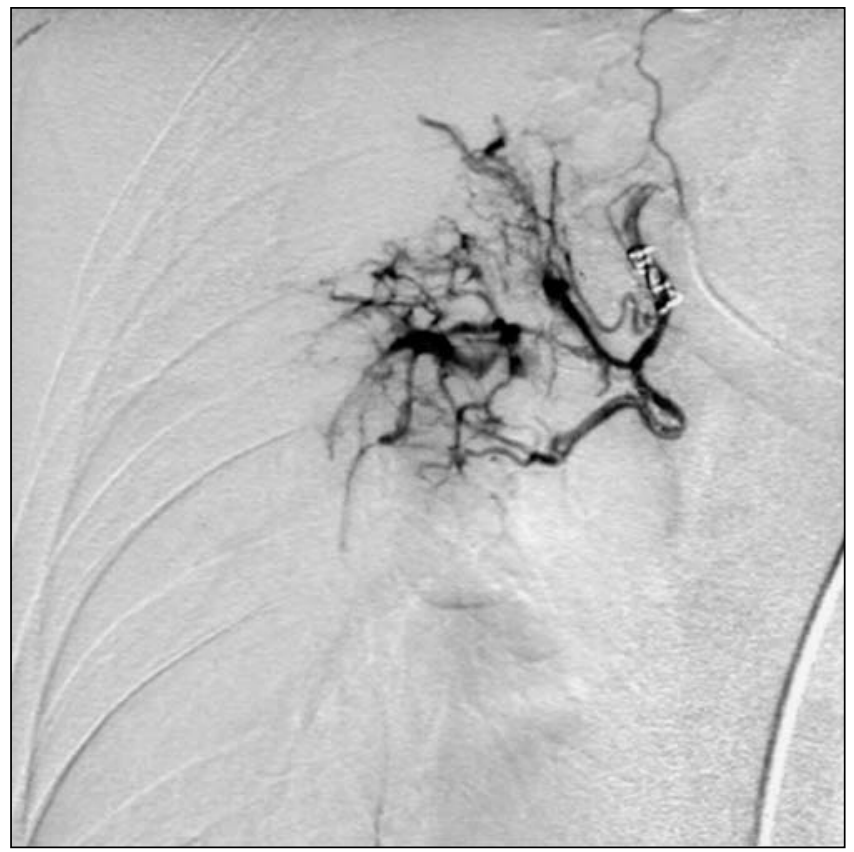

Figure 4) Bronchial angiogram demonstrating recurrence of abnormal vessel formation on the right side

upper lobe bronchus. Bronchial angiography showed extensive revascularization and abnormal vessels throughout the right upper zone. Arterial venous malformation (AVM) was seen in the left upper lobe at a similar position as the previous AVM but arising from a separate vessel, and successful embolization was completed. The original site was still occluded. Since that time, the patient has been admitted on two more occasions with hemoptysis, and on each occasion, he underwent successful embolization.

\section{DISCUSSION}

Dieulafoy's disease is a vascular anomaly characterized by the presence of a dysplastic artery that is related to an epithelial ulcer. It was first described as a lesion in the stomach (1), but it appears to occur throughout the digestive tract (2).

Although it is most frequently a gastrointestinal condition, a handful of cases affecting the bronchus have been described in the literature recently $(3-6)$. It is interesting to note that it has been reported in patients with healed pulmonary tuberculosis and in such cases, it affects the upper lobes, a site associated with tuberculosis $(4,6)$. Massive hemoptysis from old tuberculosis with bronchiectasis, especially in the upper lobes, is well known; however, in our patient, a computed tomography scan of the chest excluded bronchiectasis and mycetoma.

In the case report by Van der Werf et al (4), bronchoscopy and bronchial biopsy from such a lesion led to fatal hemorrhage. Hence, it is important to consider Dieulafoy's disease as a cause for massive hemoptysis, especially in patients with a past history of pulmonary tuberculosis, and defer biopsy at the time of bronchoscopy in such cases. In the case reported by Hope-Gill and Prathibha (6), bronchial washing with normal saline led to moderate hemorrhage and the procedure had to be abandoned. In our patient, the first bronchoscopy was nor- 
mal, while the second showed fresh blood in the left upper lobe bronchus.

Patients with Dieulafoy's disease treated with embolotherapy may develop recurrence of the AVM and, hence, should be under regular follow-up care. Recurrence of hemoptysis in

\section{REFERENCES}

1. Dieulafoy G. Exulceratio simplex. L'intervention chirurgicale dans les hémateméses foudroyantes consecutives a l'exulcération simple de l'estomac. Bull Acad Med 1898;49:49-84.

2. Dy NM, Gostaut CJ, Balm RK. Bleeding from the endoscopically identified Dieulafoy lesion of the proximal small intestine and colon. Am J Gastroenterol 1995;90:108-11.

3. Sweerts M, Nicolson AG, Goldstraw P, et al. Dieulafoy's disease of the bronchus. Thorax 1995;50:697-8. these patients should be investigated with bronchial arteriography and treated accordingly. The bronchoscopic appearance of a vascular anomaly in such patients is not diagnostic, because the aberrant vessel may be covered by normal overlying mucosa and the lesion may be nonpulsatile (4).

4. Van der Werf TS, Timmer A, Zijlstra JG. Fatal haemorrhage from Dieulafoy's disease of the bronchus. Thorax 1999;54:184-5.

5. Stoopen E, Baquera-Heredia J, Cortes D, Green L. Dieulafoy's disease in association with a paravertebral neurilemoma. Chest 2001;119:292-4.

6. Hope-Gill B, Prathibha BV. Bronchoscopic and angiographic findings in Dieulafoy's disease of the bronchus. Hosp Med 2002;63:178-9. 


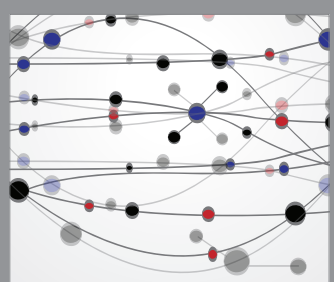

The Scientific World Journal
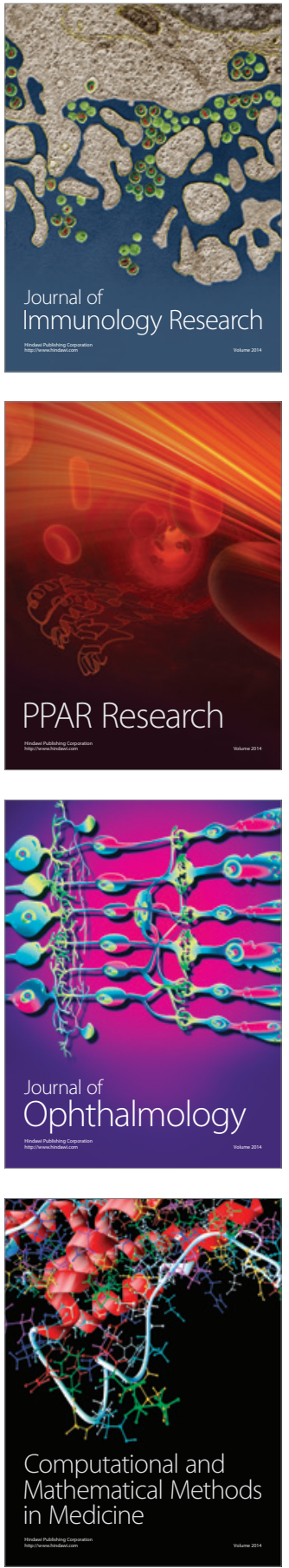

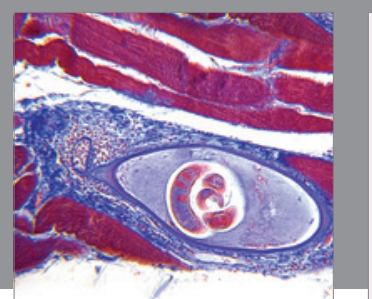

Gastroenterology Research and Practice

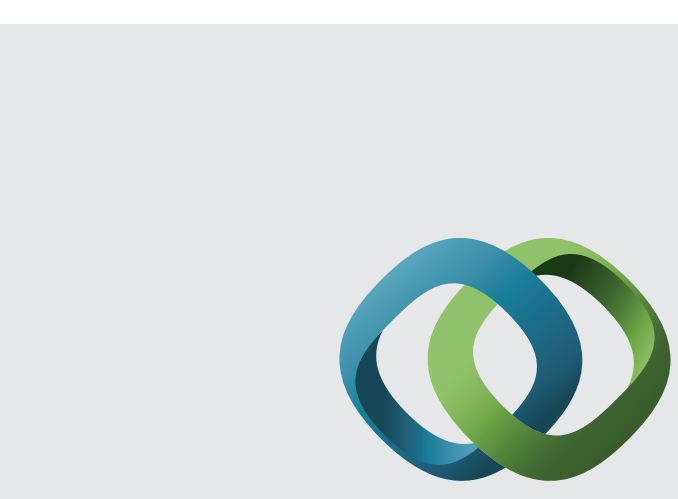

\section{Hindawi}

Submit your manuscripts at

http://www.hindawi.com
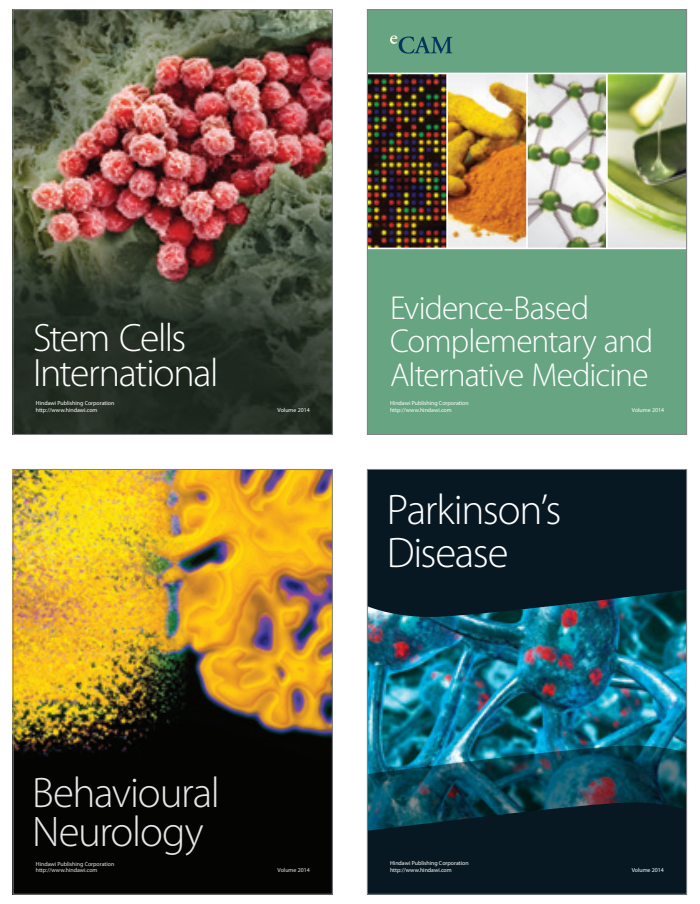
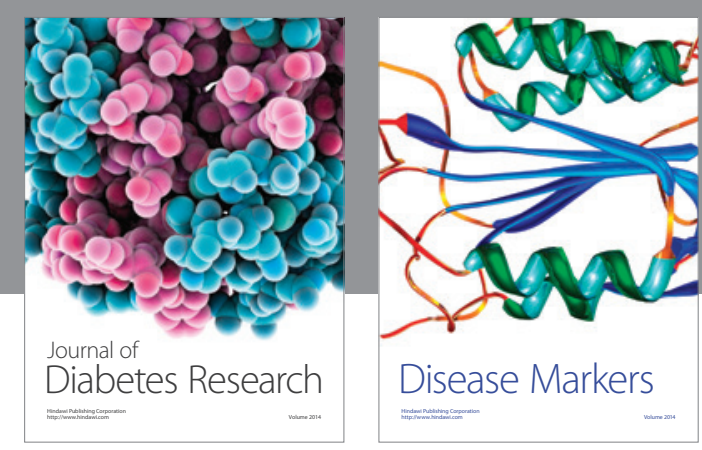

Disease Markers
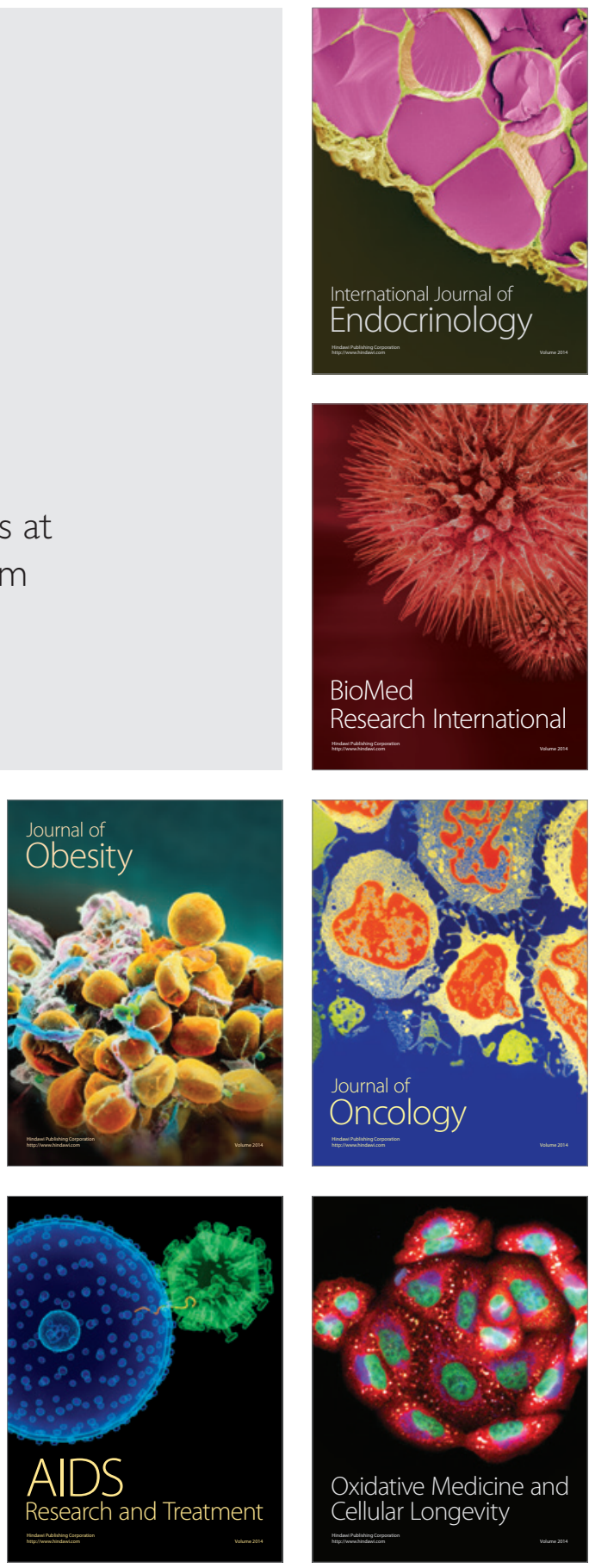